\title{
Classification and Evaluation of Porous Bioclastic Limestone Reservoir Based on Fractal Theory
}

\author{
Xiaowei Sun \\ PetroChina Research Institute of Petroleum Exploration \& Development, Beijing, China \\ Email: riped_sxw@outlook.com
}

How to cite this paper: Sun, X.W. (2016) Classification and Evaluation of Porous Bioclastic Limestone Reservoir Based on Fractal Theory. Open Access Library Journal, 3: e3026.

http://dx.doi.org/10.4236/oalib.1103026

Received: September 1, 2016

Accepted: October 7, 2016

Published: October 10, 2016

Copyright $\odot 2016$ by author and Open Access Library Inc.

This work is licensed under the Creative Commons Attribution International

License (CC BY 4.0).

http://creativecommons.org/licenses/by/4.0/

\begin{abstract}
The conventional method of classifying and evaluating reservoir based on structural features of microscopic pore has limitation. In order to realize quantitative classification and evaluation of complicated reservoir by fractal theory, the paper used mercury penetration materials to calculate fractal dimension of reservoir's pore structure, and gathered statistics to analyze the relation between fractal dimension and microscopic pore structure parameter, highlighted geological significance of fractal dimension, believing that fractal dimension of reservoir's pore structure comprehensively and qualitatively characterizes complication degree of reservoir' pore structure. The smaller the fractal dimension is, the weaker the reservoir's microscopic heterogeneity is and the better the reservoir's quality is. Based on this, fractal dimension is applied to classify and evaluate pore-type bioclastic limestone reservoir, and it shows that the reservoir is clearly partitioned. Besides, the reservoir is divided quantitatively into high quality reservoir, good reservoir, bad reservoir, worse reservoir and invalid reservoir according to size of fractal dimension, thereby realizing quantitative classification and evaluation of complicated reservoir.
\end{abstract}

\section{Subject Areas}

Geology

\section{Keywords}

Microscopic Pore Structure, Fractal Dimension, Bioclastic Limestone, Classification and Evaluation of Reservoir

\section{Introduction}

Reservoir classification and evaluation are important contents in research on reservoir, and an important method for this research is to start from structural features of reser- 
voir's microscopic pore and synthesize reservoir's physical parameters for reservoir classification and evaluation [1]-[5]. The predecessors have put forward a lot of methods to classify and evaluate reservoir based on structural features of reservoir's microscopic pore, which are generalized into two: the first is experience division method, and the second is clustering method, which two conventional methods, however, have some limitations, as the former is greatly influenced by subjective human factors, while the latter can only get accurate and perfect result based on large amount of basic materials [6]-[10].

Microscopic pore structure of reservoir rock has good statistical self-similarity, and shows good fractal characteristics within certain pore diameter scope, which can be quantitatively described by fractal dimension. Based on different test means, many scholars put forward diversified calculation methods to get fractal dimension and applied fractal dimension to quantitatively description of reservoir's microscopic pore structure and microscopic heterogeneity, thereby providing a way to quantitatively classify and evaluate reservoir based on microscopic pore structure [11] [12]. The reservoir in Cretaceous Mishrif formation in W oil field has stronger heterogeneity [13], and is greatly influenced by microscopic pore structure. The reservoirs with the same porosity but different pore structure show great differences in permeability. Applying the conventional method to classify and evaluate reservoir is difficult to get satisfactory results.

With mercury penetration material, the paper calculated fractal dimension of reservoir's pore structure in the researched area according to fractal theory, and further explored geological significance of fractal dimension by analysis on the relation between fractal dimension and microscopic pore structure parameter. Meanwhile, the application of fractal dimension to classify and evaluate reservoir shows that reservoir is well partitioned, thereby realizing quantitative classification and evaluation of complicated reservoir.

\section{Calculation Method of Fractal Dimension}

The fractal dimension of the pore structure can be obtained based on mercury penetration test. Mercury saturation at different inlet mercury pressures can be got by mercury penetration test, while the inlet mercury pressure corresponds to certain pore throat radius, and mercury saturation reflects the probability of the volume of pore greater than this pore throat radius in total pore volume. According to the two's relation, fractal dimension of the pore structure can be obtained. The concrete principle and computation process is as follows [14] [15]:

According to fractal geometry theory, if reservoir's pore structure conforms to fractal structure, then number $N(r)$ of pore greater with pore diameter greater than $r$ in reservoir and $r$ is in power function relation:

$$
N(r) \propto r^{-D}
$$

where, $N(r)$ is number of pore throat, $r$ is radius of pore throat, $\mu \mathrm{m} ; D$ is fractal di- 
mension.

$$
N(r)=\frac{V_{h g}}{\pi r^{2} l}
$$

where, $l$ is length of capillary tube, $\mathrm{cm} ; V_{h g}$ is the corresponding volume of accumulative mercury flowing across pore throat with a radius of $r, \mathrm{ml}$.

From formula (1) and (2), we get:

$$
V_{\mathrm{hg}} \propto r^{2-D} .
$$

Capillary pressure $P_{c}$ is:

$$
P_{c}=\frac{2 \sigma \cos \theta}{r}
$$

where, $P_{c}$ is capillary pressure, Mpa; $\sigma$ is interfacial tension, $\mathrm{mN} / \mathrm{m} ; \quad \theta$ is the angle of contact, $\left({ }^{\circ}\right)$.

Substitute formula (4) into formula (3):

$$
V_{\mathrm{hg}} \propto P_{c}^{-(-2-D)} .
$$

According to definition of mercury saturation in rock sample, we get:

$$
S_{\mathrm{hg}}=\frac{V_{h g}}{V_{p}} \times 100 \% .
$$

From formula (5) and formula (6), we get:

$$
S_{\mathrm{hg}}=a P_{c}^{-(2-D)}
$$

where, $a$ is scale factor.

From formula (7), it is observed that if rock sample's microscopic pore structure is fractal, then mercury saturation and capillary pressure should meet power function relation, and they are a straight line in log-log coordinate system, with slope of 2-D straight line. The above method is used to calculate fractal dimension of microscopic pore structure for 43 rock samples in Cretaceous Mishrif formation in W oil field to show that reservoir's microscopic pore structure appears as fractal structure within certain scale scope, and fractal dimension is between 2.01 and 2.79, which is a large span of fractal dimension, indicating strong reservoir heterogeneity.

\section{Geological Significance of Fractal Dimension}

From relation (1) of fractal characteristics of reservoir's pore structure, it is observed that the number $N(r)$ of pores with pore diameter greater than $r$ in log-log coordinate and $r$ conform to power function relation. The slope represents fractal dimension; in mathematical significance, fractal dimension reflects the speed by which the pore number changes with change of characteristic scale of pore diameter; its physical significance can be explained as the concentration degree of pore throat size distribution. The bigger the fractal dimension is, the higher the concentration degree of pore is. To further highlight geological significance of pore structure fractal dimension, this re- 
search made a statistical analysis on the relation between conventional parameters of reservoir's pore structure and fractal dimension.

\subsection{Relation between Fractal Dimension and Parameter of Pore Throat Size}

Pore throat radius median $\left(\mathrm{R}_{50}\right)$ is the pore radius corresponding to accumulative volume $50 \%$ on the cumulative distribution curve, being an important parameter characterizing size of reservoir's microscopic pore. Figure 1 shows the statistical relationship with fractal dimension, it is observed that fractal dimension and pore radius median appear as good negative correlation, indicating the smaller the fractal dimension is, the greater the reservoir's pore radius is. The better the reservoir's reservoir property is, the higher the likelihood of oil gas accumulation is under the same reservoir-formation background.

\subsection{Relation between Fractal Dimension and Parameter of Pore Throat Separation Characteristic}

Figure 2 shows the statistics of the relation between reservoir's fractal dimension and relative separation factor of reservoir's pore throat. It can be found that fractal dimension and relative separation factor of pore throat appear as good positive correlation, which conclusion is consistent with physical significance represented by fractal dimension. The relative separation factor of pore throat reflects distribution uniformity of reservoir's pore throat. The smaller the fractal dimension is, the smaller the deviation of distribution of reservoir rock's pore size from mean of pore throat is, the evener the pore throat distribution is, the weaker the microscopic heterogeneity is, and the better the reservoir quality is [16] [17].

Above analysis shows that the geological significance of fractal dimension of reservoir's pore structure can be comprehended as comprehensive representation of

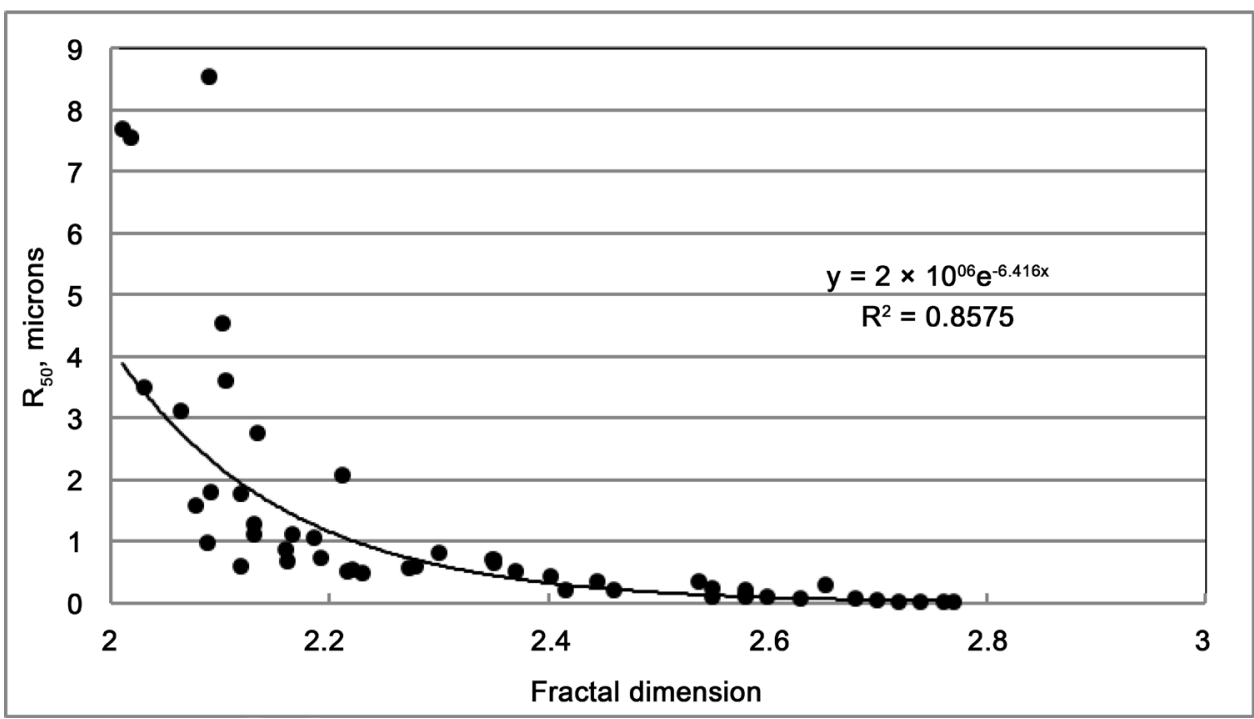

Figure 1. Curve of relation between pore throat median radius and fractal dimension. 


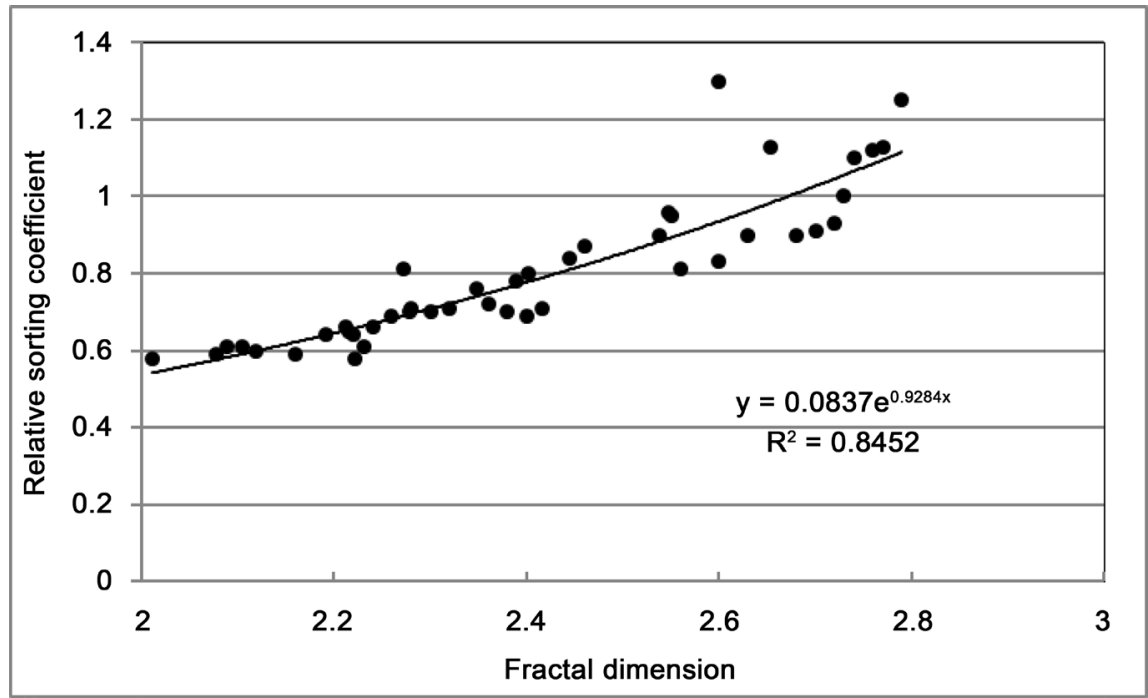

Figure 2. Curve of relation between pore throat relative sorting coefficient and fractal dimension.

complication degree of reservoir's pore structure. The smaller the fractal dimension of reservoir's pore structure is, the greater the reservoir's maximal connection pore throat radius and average pore radius is, then the smaller the drag hindering fluid flow is. Meanwhile, the evener distribution of reservoir's pore throat is, the weaker the microscopic heterogeneity is, and the better the reservoir quality is. Fractal dimension can fill up the deficiency of using single conventional pore throat parameter to reflect characteristics of reservoir's pore structure and realize quantitative assessment on reservoir's microscopic heterogeneity.

\section{Quantitative Reservoir Classification and Evaluation}

The reservoir of Cretaceous Mishrif formation in $\mathrm{W}$ oil field is mainly organic reef bank deposit with rich content of biodetritus and less crack development, being typical pore-type bioclastic limestone reservoir. The general lithologic character is complicated, and the reservoir has quickly changed precipitation facies and stronger heterogeneity. Besides, the diagenesis of reservoir of different lithologic characters between different precipitation facies belts is greatly different. The reservoir's microscopic pore structure can obviously control reservoir's quality. Permeability for reservoir with same porosity yet different pore structures tends to be hugely different. The statistical analysis on the relation between reservoir's fractal dimension of pore structure and reservoir's physical parameters indicates that fractal dimension and porosity have no obvious correlation, but have significant negative correlation with reservoir permeability, which shows in Figure 3, and the correlation coefficient is up to 0.9189 . With increase of fractal dimension, permeability shows obvious decrease trend. Meanwhile, reservoir samples are significantly partitioned, and Figure 4 shows that the reservoir can be quantitatively divided into 5 categories according to size of fractal dimension. See Table 1 for physical properties and pore structure parameters of different reservoirs, and Figure 5 shows the classification of reservoir and corresponding pore throat radius 


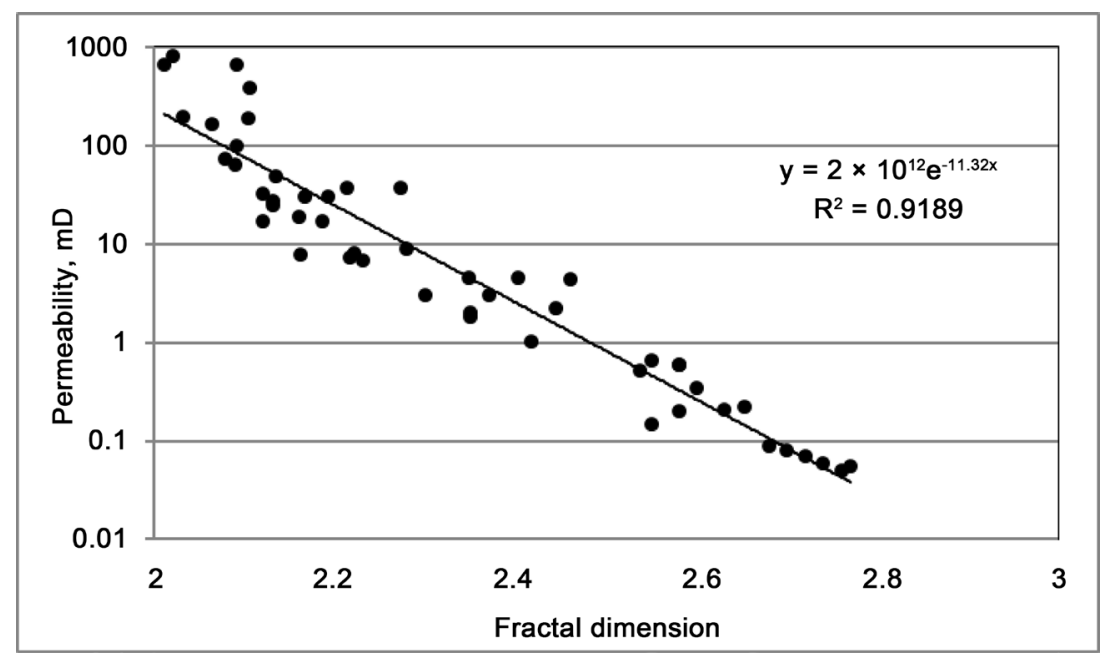

Figure 3. Curve of the relation between permeability and fractal dimension.

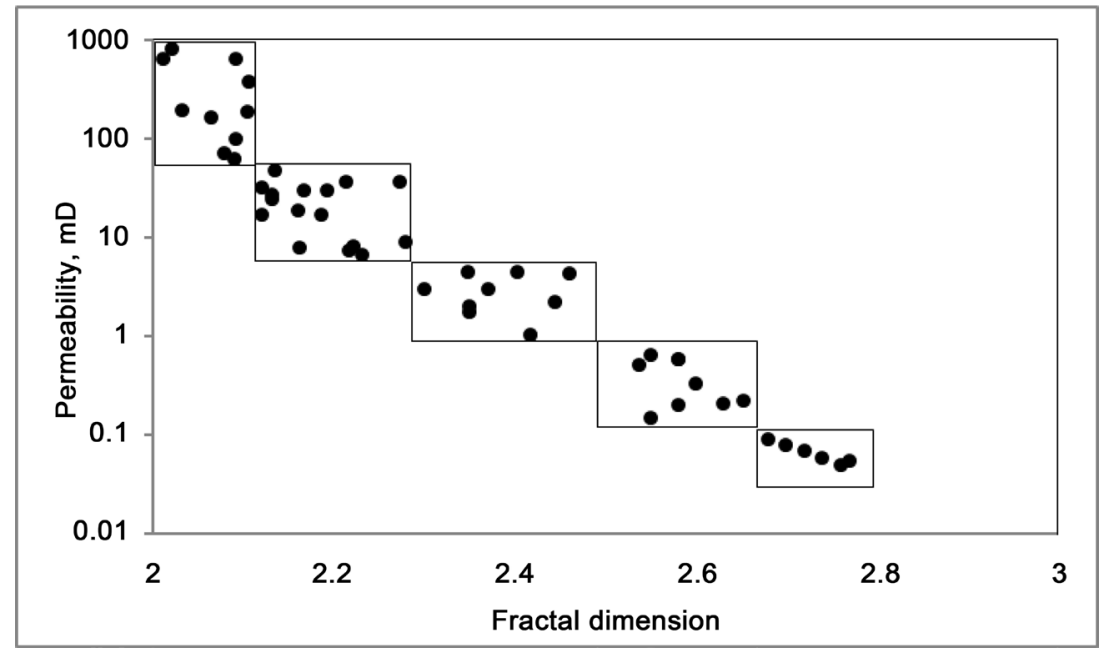

Figure 4. Reservoir classification chart based on fractal characteristics.

Table 1. Quantitative classification and evaluation table of the reservoir based on fractal characteristics of pore structure.

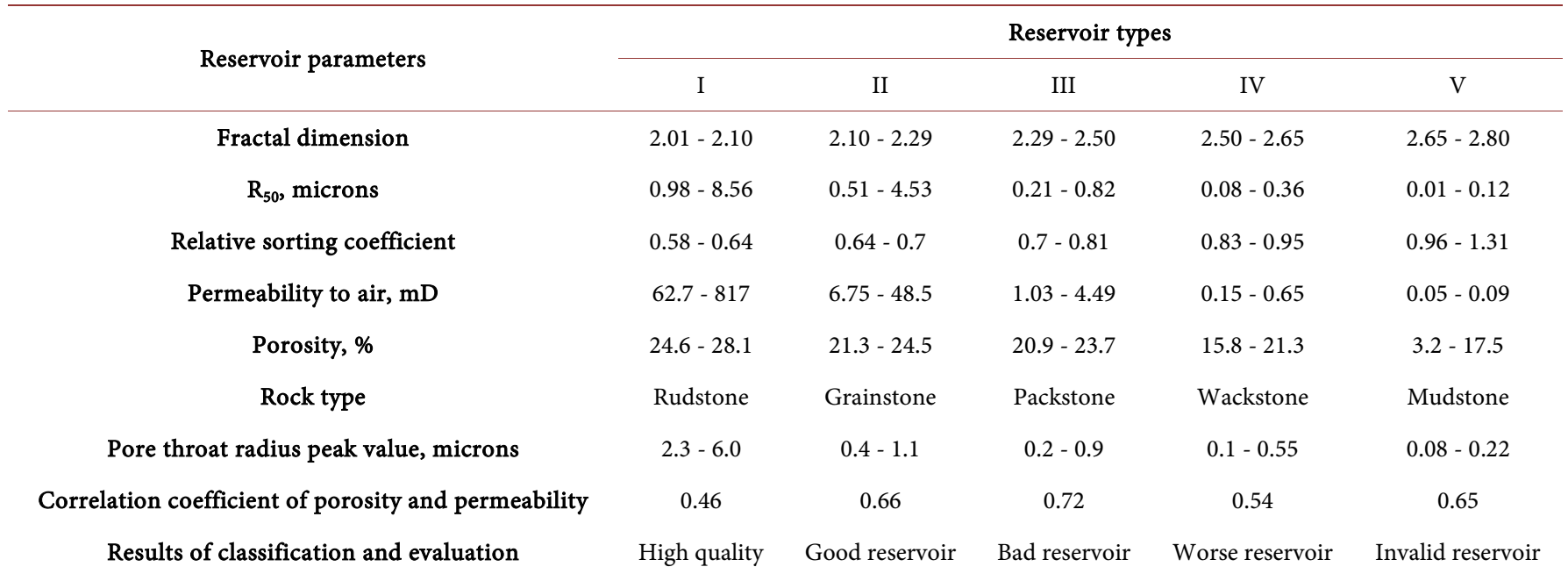



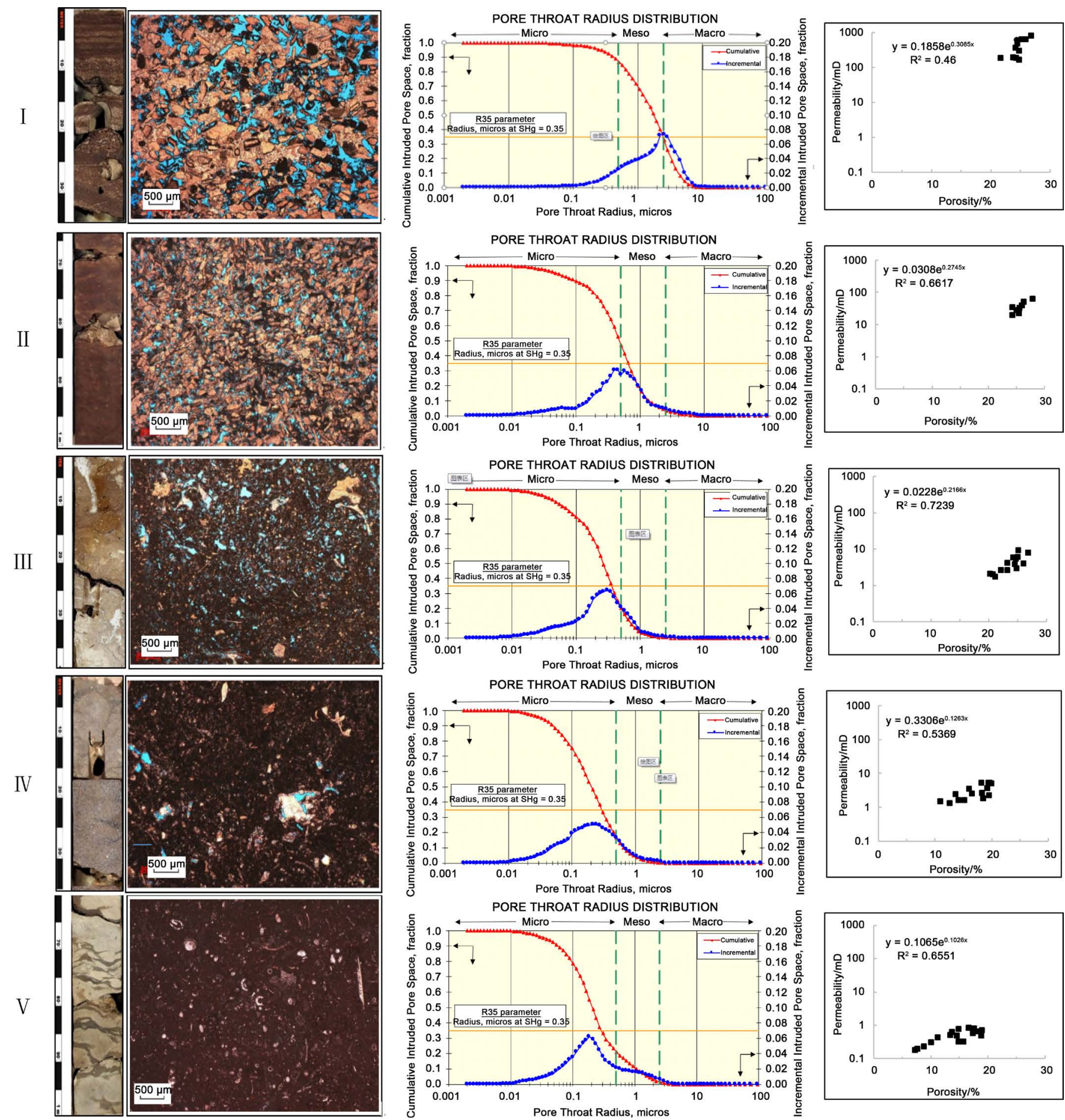

Figure 5. The classification of reservoir and corresponding pore throat radius distribution and porosity-permeability.

distribution and porosity-permeability relationship.

I Category: The fractal dimension of reservoir's pore structure is small, with an average of 2.05. The reservoir's rock type is mainly rudstone, and it has the best petrophysical property. Due to the reservoir's pore types are mainly intergranular pores and mol- 
dic pores, and throats are mostly the reduced part of pores, the pores and throats have good connectivity and strong seepage capacity. The pore throat median radius is high and relative separation factor is low, mostly belonging to macropores with coarse throats. The correlation coefficient of porosity and permeability is 0.46 .

II Category: Fractal dimension of reservoir's pore structure is small, with an average of 2.19. The reservoir's rock type is mainly grainstone, and it has good petrophysical property. Due to the reservoir's pore types are mainly residual intergranular pores and intergranular dissolved pores, and the throat is mostly contraction part of the changeable section between particles. The pore throat connectivity and seepage capacity are good. The pore throat median radius is great, and pore throat distribution is relatively even. The porosity and permeability have good correlation with correlation coefficient of 0.66 .

III Category: Fractal dimension of reservoir's pore structure is of middle level, with an average of 2.38. The reservoir's rock type is mainly packstone, and it has good middle-level petrophysical property. Due to the pore types of reservoir are mainly intergranular dissolved pores and intragranular dissolved pores, and the throat is mostly of flake shape or curved flake shape, the pores and throats have middle connectivity and seepage capacity. The pore throat median radius is of middle level and distribution of pore throat is even, most belonging to type of fine pore fine throat. The porosity and permeability have good correlation with correlation coefficient of 0.72 .

IV Category: Fractal dimension of reservoir's pore structure is great, with an average of 2.57. The reservoir's rock type is mainly wackstone, and it has good middle-level petrophysical property. Due to the pore types of reservoir are mainly intragranular dissolved pores and inter-crystalline dissolved pores, and the throat is mostly reduced throat, the pores and throats have low connectivity and permeability. The pore throat median radius is small and distribution of pore throat is uneven, most belonging to extra fine pore throat. The correlation coefficient of porosity and permeability is 0.52 .

V Category: Fractal dimension of reservoir's pore structure is great, with an average of 2.69. The rock type is mainly mudstone, and it has the worst petrophysical property. The pore types are mainly intragranular dissolved pores and matrix pores. The throat is mostly pipe column shaped throat with low connectivity and seepage capacity. The pore throat median radius is small and pore throat distribution is extremely uneven. The correlation coefficient of porosity and penetration is 0.65 .

\section{Summary}

From the studies above, it can be found that the smaller the fractal dimension is, the greater the reservoir's maximal connection pore throat radius and average pore radius are, the evener the distribution of reservoir's pore throat is, the higher the pore throat connectivity is, the stronger the seepage capacity is, the weaker the reservoir's microscopic heterogeneity is, and the better the reservoir's quality is. Applying fractal dimension to reservoir classification and evaluation shows the reservoir is well partitioned. 


\section{Conclusion}

Fractal dimension of reservoir's pore structure is comprehensive quantitative representation of complication degree of reservoir's pore structure, and reservoir classification and evaluation can be conducted quantitatively according to the size of fractal dimension, indicative of strong practicability of this method.

\section{References}

[1] Wang, Y.C. (1999) Evaluation of Oil and Gas Reservoirs. Petroleum Industry Press, Beijing, 75-81.

[2] Meng, Q.F. and Hou, G.T. (2011) Layer Thickness Controls on Surface Density and Fractal Dimension of Structural Fractures in Carbonate Strata. Geology Journal of the China Universities, 17, 462-468.

[3] Zuo, J., Xu, W.Y. and Wang, H.L. (2014) Fractal Analysis of SEM Image for Rocks. Journal of China Three Gorges University (Natural Science), 36, 72-83.

[4] Perez, G. and Chopra, A.K. (1997) Evaluation of Fractal Models to Describe Reservoir Heterogeneity and Performance. SPE Formation Evaluation, 12, 65-72. http://dx.doi.org/10.2118/22694-PA

[5] Zhang, X.G., Zhang, T. and Lin, C.Y. (2013) Pore Structure Evaluation of Low Permeability Reservoir Based on Pore Fractal Features. Lithologic Reservoirs, 25, 40-45.

[6] Luo, M.G. (1998) Quantitative Reservoir Geology. Geological Publishing House, Beijing, 92-101.

[7] Xia, W.F., Xia, Z.Y. and Wang, Z.Q. (2015) Fractal Fecture about the Pore-Structure and Its Evaluation of E2-3Z3 Reservoir in Huomatu Anticlinal Zone of Zungaer Basin. Science Technology and Engineering, 15, 107-113.

[8] Li, H.Y. and Xu, Z.Y. (2009) Micro Pore Structure and Classification Evaluation of Low Permeability Reservoirs in the New Oil Field. Petroleum Geology and Recovery Efficiency, $16,17-21$.

[9] Ehrburger-Dolle, F., Lavanchy, A. and Stoeckli, F. (1994) Determination of the Surface Fractal Dimension of Active Carbons by Mercury Porosimetry. Journal of Colloid \& Interface Science, 166, 451-461. http://dx.doi.org/10.1006/jcis.1994.1317

[10] He, W., Zhong, F.Y. and He, C.Z. (2000) Fractal Texture Reservoir on the Pores in Reservoir Rocks and Its Application. Natural Gas Industry, 20, 67-70.

[11] Liu, Y.K., Wang, Y.P. and Tang, H.M. (2014) Application of Capillary Pressure Curves and Fractal Theory to Reservoir Classification. Lithologic Reservoirs, 26, 89-94.

[12] Ma, X.F., Zhang, S.C. and Lang, Z.X. (2004) Calculation of Fractal Dimension of Pore Structure by Using Subsection Regression Method. Journal of the University of Petroleum, China, 28, 54-60.

[13] Bai, G.P. (2007) Oil and Gas Geological Characteristics of Middle East Oil and Gas Fields. China Petrochemical Press, Beijing, 16-20.

[14] Bai, R.T., Li, Z.P. and Nan, J.X. (2016) The Fractal Permeability Model in Tight Sand Reservoir Accounts for Start-Up Gradient. Natural Gas Geoscience, 27, 142-148.

[15] Zhang, T., Xu, S.Y. and Yang, K. (2010) Application of Fractal Dimension of Micro Pore Structure of Reservoir. Journal of Daqing Petroleum Institute, 34, 44-47.

[16] Shen, J.S. and Zhang, H.K. (2008) Study on the Heterogeneity of the Pore Structure of Chang 6 Reservoir in ZJ Oilfield, Erdos Basin Using Fractal Theory. Journal of Xi an Shiyou 
University (Natural Science Edition), 23, 19-23.

[17] Dou, W.C., Liu, L.F. and Wu, K.J. (2016) Pore Structure Characteristics and Its Effect on Permeability by Mercury Injection Measurement: An Example from Triassic Chang-7 Reservoir, Southwest Ordos Basin. Geological Review, 62, 502-511.

Submit or recommend next manuscript to OALib Journal and we will provide best service for you:

- Publication frequency: Monthly

- 9 subject areas of science, technology and medicine

- Fair and rigorous peer-review system

- Fast publication process

- Article promotion in various social networking sites (LinkedIn, Facebook, Twitter, etc.)

- Maximum dissemination of your research work

Submit Your Paper Online: Click Here to Submit

Or Contact service@oalib.com 